\title{
Breve reflexão sobre a importância do método científico
}

\section{Brief reflection on the importance of the scientific method}

\author{
Marília Vizzotto* \\ Valquiria Rossi* \\ Maiango Dias* \\ Roberto Rusticci* \\ Cecília V. Farhat* \\ AndRÉ ReIDHL*
}

\section{Resumo}

Este texto faz uma reflexão sobre o Método Científico como a maneira segura e viável para se alcançar uma explicação acerca de um objeto ou fenômeno. Com o uso do método se conhece e sistematizam-se os objetos ou fenômenos, pois ele possibilita o acréscimo ao conhecimento científico e também abre caminhos para a ciência questionar seus próprios achados e refutar conhecimentos já adquiridos.

Palavras-chave: método científico; ciência; refutação

\section{Abstract}

This text makes a reflection on the Scientific Method as the safest and viable way to reach an explanation about an object or phenomenon. With the use of the method the objects or phenomena are known and systematized, since it allows the addition to the scientific knowledge and also opens up ways for the science to question its own findings and to refute knowledge already acquired.

Keywords: scientific method; science; refutation

* Programa de Stricto Sensu [Mestrado/doutorado] em Psicologia da Saúde da Escola de Ciências Médicas e Saúde da Universidade Metodista de São Paulo. 


\section{Introdução}

Este texto faz uma reflexão sobre o Método Científico como a maneira segura e viável para se chegar a uma explicação acerca de um objeto ou fenômeno; destacando-se, pois, que "método" é um caminho traçado para se chegar a um determinado lugar (lugar esse que nada mais é do que o objetivo/meta anteriormente lançado). A palavra método, conforme definição de dicionário (FERREIRA, 2010) vem do grego méthodos, que quer dizer "caminho para chegar a um fim"; e Luft (2003) também esclarece que método é a maneira de ordenar a ação de acordo com alguns princípios. Lembramos ainda, que a descrição do passo a passo realizada para se atingir esse determinado objetivo definido anteriormente, trata-se do delineamento ou desenho do estudo feito por um pesquisador, o que também merece destaque.

O Método então, conforme Cervo e Bervian (1978) é a ordem que se deve impor aos diferentes processos necessários para atingir um dado fim ou um resultado desejado. De modo que, nas ciências, entende-se por método o conjunto de processos que o espírito humano deve empregar na investigação e demonstração da verdade.

Sabemos, entretanto, que a Ciência, seu método e seus delineamentos sofrem muitas críticas. Tais críticas, e muitas delas admissíveis, são tidas não só pelo raciocínio objetivo ou pelo pensamento cartesiano inaugurado com Descartes, mas por suas conseqüências na sociedade, na natureza, ou seja, no mundo. As mudanças provocadas pelo desenvolvimento científico/tecnológico sejam ambientais ou transformações da sociedade, implicam numa nova ordem mundial e vêm criando novos efeitos sobre o modo de vida das pessoas.

A crítica parte então do uso que se faz da ciência ou de sua conseqüente tecnologia, mais do que à Ciência em si mesma? A esse respeito Kerlinger (1979) já escrevera que a Ciência não foi feita para evitar guerras e nem tampouco para fazê-las. Nesse sentido o autor quer enfatizar a neutralidade da ciência e de seu método na investigação do fenômeno. Mas, por outro lado, será que o pensamento cartesiano não tenha propiciado a dicotomia homem - natureza? $\mathrm{Na}$ maneira cartesiana de entender o mundo, o homem pode dominar a natureza e tomar posse dela, e essa dicotomia é advinda da própria divisão feita por Descartes entre espírito e matéria. 
Mas, se não tivéssemos a Ciência .......... Teríamos o senso comum e outros conhecimentos que não nos possibilitam sistematizar!

\section{Senso Comum e outros conhecimentos não científicos}

É importante destacar, conforme explicou Ruiz (1979) que conhecimento só é possível por meio de três elementos: o sujeito cognoscente (que conhece) o objeto (conhecido) e a imagem. O sujeito é aquele que detém o conhecimento, o objeto é aquele que será conhecido, e a imagem é a interpretação dada ao objeto pelo próprio detentor - o sujeito. E esse conhecimento é que leva o homem a apropriar-se da realidade e tornar-se apto para a ação.

Mas como se dá esse conhecimento? Antes do nascimento da Ciência e propriamente do marco histórico dado pelos historiadores como sendo com Galileu Galilei, os indivíduos experimentam em sua rotina diária todo conhecimento advindo das crenças adquiridas, do conhecimento teológico, e da experiência do dia-a-dia.

É então possível dizer que, àquilo que é comum e experimentado no dia-a-dia, estão: o conhecimento religioso e o conhecimento filosófico. Conforme nos explica Appolinário (2006) uma das formas utilizadas para explicar e organizar o mundo é a crença de que existe uma força superior, divina, produto da fé e da transcendência que determina os destinos do universo; o conhecimento religioso tem como principal característica o dogma, ou seja, não pode ser testado ou questionado. Outra forma de conhecimento é o artístico que é embasado na emoção e na intuição e é essencialmente não racional, embora possa assumir qualquer forma, pois o importante é a relação que se estabelece entre o observado e o fenômeno. Já o conhecimento filosófico é baseado na razão, porém, não busca comprovação empírica acerca dos fatos

Aquilo que é experimentado no cotidiano, o senso comum, é todo o conhecimento vulgar, comum, corriqueiro, ou ainda a compreensão do mundo que resulta daquilo que fora acumulado por meio de experiências. Trata-se, então, do conjunto de conhecimentos e de crenças populares considerados válidos, embora sem nenhum tipo de sistematização científica. 
O senso comum, explica Volpato (2013), não seria uma forma particular de conhecimento e sim uma mistura desordenada destas outras formas; tudo o que aprendemos com o senso comum torna-se validado pelos critérios pessoais de aceitação, caracterizados por aquilo que é corriqueiro ou ainda baseado nas crenças.

Neste sentido, Alves (2013) ensina que senso comum é a percepção dos acontecimentos do nosso dia a dia que é muito utilizado; normalmente vem antes do conhecimento da ciência e é a forma de conhecimento mais utilizada por pessoas comuns. $\mathrm{O}$ senso comum é uma crença não justificada ou pode-se dizer que é uma explicação de algo sem a verificação de uma comprovação, ou seja, sem questionamentos, são as crendices que pode vir das religiões, superstições, entre outras formas de crenças. Então, não está diante de uma investigação científica e sim, de uma tradição ou de uma experiência coletiva de uma determinada comunidade.

$\mathrm{O}$ autor argumenta que o senso comum pode nascer de uma experiência pessoal acumulada que está fortemente baseado na percepção. Ele é acrítico, pois, não tem justificativa com as representações na realidade, isto é, não fornece a explicação nem permite a compreensão da realidade.

O senso comum, continua Ruben Alves, se apóia na tradição e não na investigação. Exemplo, quando temos a seguinte informação: 'não devemos nadar depois de comer', essa informação é somente passada verbalmente, mas não existe uma explicação científica, só existe a credibilidade de que não devemos nadar após nos alimentar. Então, a explicação do motivo de que é prejudicial nadar depois de comer teve que ser dado pela Ciência, pois a ciência é o aprofundamento do conhecimento a partir do senso comum (ALVES, 2013).

Porém, como explica Appolinário (2006) o senso comum também adquire uma importância em nosso dia-a-dia, uma vez que em todos os momentos temos de tomar decisões como, por exemplo, comprar uma calça ou definir qual melhor marca de creme dental; e essas decisões seriam impraticáveis caso tivéssemos que utilizar um método científico para cada uma delas. Talvez, acrescentamos, seja muito mais viável dizer que utilizamos o "bom senso", que serve para integrar os indivíduos nos comportamentos e valores estabelecidos pela sociedade e orientar a nossa vida. 


\section{método científico}

O método científico surge com a Ciência Moderna após a decadência da Idade Média que compreendeu o período do século $\mathrm{V}$ ao XV (datado por historiadores). Com o Renascimento (séculos XIV e XVI) houve um intenso intercâmbio de conhecimento a respeito de antigos tratados sobre astronomia e física, bem como o aperfeiçoamento de instrumentos de navegação, como a luneta e mais tarde telescópio, por Galileu Galilei. Antes, porém, foi o polonês Nicolau Copérnico que hipotetizou sobre o cosmos e heliocentrismo - indicando a idéia da terra girando em torno da órbita do Sol. A hipótese de Copérnico foi confirmada mais tarde por Galileu Galilei - considerado o "pai da ciência moderna".

Galileu então, confirma, comprova a hipótese ao criar o telescópio - com o qual se pôde observar os corpos celestes, alcançar a visualização das imperfeições na Lua e em outros planetas; o que contestou a antiga concepção de um cosmos fechado. Com isso, seguiu Kepler, entre outros cientistas, a compreenderem uma nova forma de concepção do mundo físico. A ideia da busca constante de explicações, soluções, bem como de novas avaliações de resultados ganhou forças a partir do século XVI.

O método científico passa então a ser concebido como um conjunto de regras básicas para desenvolver uma experiência, a fim de produzir novo conhecimento, bem como corrigir e integrar conhecimentos pré-existentes. A ciência passa também a ser definida, conforme Apollinário (2006) como uma das formas de conhecimento, coexistindo com a religião, com a arte, com a filosofia e com o próprio senso comum.

Destaca-se, porém, que a ciência moderna surge aceitando somente os conhecimentos embasados em evidências empíricas, ou seja, a obtenção de alguma evidência "concreta" do mundo sensível é sempre necessária (VOLPATO, 2013).

E para a obtenção destas evidências é necessário a utilização de um método; por isso o método científico é tido, conforme Marconi e Lakatos (2000), como o conjunto de atividades sistemáticas e racionais, que com maior segurança e economia, permite alcançar o objetivo - conhecimentos válidos e verdadeiros, traçando o caminho a ser seguido, detectando erros e auxiliando nas decisões do cientista. 
Com relação às decisões do cientista, Karl Popper - grande filósofo da ciência atual recusa a ingerência histórica e reafirma seu vínculo com o racionalismo normativo clássico. Seu interesse, segundo Gutierre (2012) não reside na procura de um método que espelhe um progresso efetivamente alcançado, mas sim na busca de uma metodologia que sustente processos de decisão empírica, assegurando a crítica (leia-se, a razão) no âmbito científico.

Popper afirma que deveríamos tentar determinar o que os cientistas "devem" ["ought"] fazer. Essa palavra "devem" obviamente não tem teor ético, embora a ética esteja também envolvida aqui, mas seria antes o "devem" de um imperativo hipotético. A questão é: "Como deveríamos proceder em caso de desejarmos contribuir para o crescimento do conhecimento científico?" E a resposta é: "Você não tem melhor alternativa que proceder conforme o método crítico de tentativa (conjectura) e eliminação do erro, procurando testar ou refutar suas conjecturas." O argumento que suporta essa resposta pertence à lógica situacional. Não penso que devemos nos voltar para a questão (sociológica) sobre o que os cientistas realmente fazem ou dizem (POPPER, 1974, p. 1036).

Com isso vale ressaltar a noção de formas de investigação e a questão da validade e confiabilidade dada por essa forma de conhecimento humano.

\section{A indução, a dedução e a questão da validade e da confiabilidade científicas}

Desde Bacon a Ciência tem por premissa de que para propor uma Lei científica é necessário testá-la repetidamente, coletar dados, verificar os resultados e propiciar a outros pesquisadores que isso se faça (replicar) para que então possa ser considerada válida. Assim, repetidas vezes os resultados similares tornarão as hipóteses válidas e se mostrará a Lei.

Com isso temos o método indutivo. Mas, Karl Popper questiona a indução tal como se mostra; e como menciona Meirelles (2002), a indução é uma inferência, pois ela passa de enunciados particulares, ou experimentos, aos enunciados universais, tais como as hipóteses ou "teorias". Popper afirmava que não se delimita pela indução o que é e o que não é ciência, uma vez que qualquer pessoa leiga pode 
elaborar um enunciado desse tipo. Assim, o que define a Ciência da não-ciência é a falseabilidade. Todos os enunciados da ciência empírica são suscetíveis de serem decididos com relação à sua verdade e falsidade; diremos que eles devem ser "decidíveis" de modo conclusivo. Isto significa que sua forma deve ser tal que deve ser logicamente possível tanto verificá-los como falseá-los. Assim, continua Meirelles (2002), para Popper, é necessário o enunciado poder ser testado empiricamente, não pela sua verificabilidade, mas pela sua falseabilidade. Dessa forma, esse autor entende que fica claramente derrubado o mito da verdade científica, sobretudo pela insuficiência de seus métodos, o que deve nos levar à reflexão de que as soluções científicas são sempre provisórias.

Assim, para Popper a solidez do enunciado que se tornará uma Lei, só poderá se dar a partir da capacidade da proposta resistir à refutação. De modo que esse autor nos dirá que: qualquer teste empírico sério consiste sempre em tentativa de encontrar refutação, um contra-exemplo. Para procurar contra-exemplos precisamos usar nosso conhecimento de base: sempre procuramos refutar em primeiro lugar as previsões mais arriscadas, as "consequências [...] mais improváveis" [...]; o que significa que sempre procuramos os contra-exemplos mais prováveis nos lugares mais prováveis - mais prováveis no sentido de que esperamos encontrá-los à luz do nosso conhecimento contextual (POPPER, 1989, p. 240).

O método dedutivo sugere que a investigação parte de um fato-problema e que a hipótese não advém da observação, mas sim criada pelo espírito humano. E as etapas de investigação do método hipotético dedutivo são: fato-problema, hipótese, dedução de consequências preditivas, a experimentação e se confirmada a hipótese, torna-se lei.

Assim, o critério popperiano de falseabilidade sustenta-se no método dedutivo de prova - um procedimento crítico para testar e selecionar hipóteses a partir de seu conteúdo informativo. As hipóteses, por sua vez, podem ser refutadas ou corroboradas pela experiência. Quanto às hipóteses cujas decisões forem positivas, porque resistiram a severos testes, estas permanecem aceitas apenas temporariamente, até que novos testes surjam e, com eles, mantenha-se a possibilidade de serem refutadas. 
Uma teoria ou sistema teórico, segundo Popper (1995, p. 32), deve ser logicamente consistente; ser empírica, não tautológica, e ser passível de comparação com outras teorias, pois ela deve representar avanço científico.

Por mais que existam críticas à ciência e seu método, é por essa via que se obtém a validade, a confiabilidade, a generalização e a possibilidade de réplica como sustentação de um construto ou paradigma.

Todavia, outro filósofo da ciência atual, Thomas Kuhn, (KUHN, 1998) reivindica como critério de verdade e de avanço científico, não o método em si, mas sim a "anomalia". Entende Tomas Kuhn que a ciência normal constrói-se a partir da presença de um paradigma. Mas, os paradigmas deixam de ser verdadeiros quando ocorre uma anomalia na rota da ciência normal e não um acúmulo de conhecimentos. Este paradigma, conforme diz Chibenni (2011), é desenvolvido e aceito a partir de estudos prévios e torna-se a base da busca e do desenvolvimento subsequente. A limitação imposta pelo paradigma faz com que um corpo de cientistas busque responder as questões que se apresentam; de modo que a soma destas respostas possibilita o desenvolvimento da ciência E é justamente por meio da ciência que se constrói conhecimento.

Cientistas como Newton, Lavoisier, Maxwell e Einstein produziram uma solução aparentemente duradoura para um grupo de problemas especialmente importantes. Seus pressupostos foram paradigmas amplamente aceitos e que suscitaram diversas pesquisas para o desenvolvimento do conhecimento (MENDONÇA; VIDEIRA, 2007). Os trabalhos acadêmicos são apresentados à comunidade científica em forma de artigos breves e apresentam conclusões que possibilitam o aperfeiçoamento e desenvolvimento dos componentes teóricos apresentados pelo paradigma.

Assim, a ciência normal é construída por acréscimos a um conhecimento inicial aceito como verdadeiro pela comunidade científica (KUHN, 1998). Entretanto, quando no decorrer destes estudos as respostas indicam uma anomalia do paradigma, tem-se uma revolução. Ocorre então o processo de substituição de um conceito por outro, implicando em sua descontinuidade. E, conforme diz Osterman (1996), embora haja uma ruptura entre as duas tradições 
de pesquisa, isso não quer dizer que o progresso científico estaria comprometido, pois o paradigma emergente passa, geralmente, a investigar os fatos que até então eram vistos como irrelevantes.

Trazendo os conceitos de Kuhn para mais próximo da nossa área de estudo, podemos exemplificar a expressão de seus conceitos nos modelos de condicionamento expostos por Pavlov e Skinner. O comportamento animal instintivo de sobrevivência permite a não variabilidade do comportamento, da mesma forma que o comportamento motor de bebês segue um padrão incontestável, independente de localização geográfica, ou raça. Na medida em que o comportamento humano se aprimora (com o desenvolvimento dos processos mentais complexos - possibilidade de inibir comportamentos instintivos) não há mais a garantia de respostas uniformes. Assim, a ciência pode tornar-se limitada a regiões, grupos, sem, entretanto, romper com os princípios que fundamentam as definições e o entendimento de ciência.

Para avaliar e ou medir uma pesquisa temos que atender a validade e confiabilidade de um instrumento. A validade é a capacidade do Instrumento em medir de fato o que se propõe a medir e existem algumas técnicas para essa verificação como: validação de conteúdo, validação aparente e análise semântica. A confiabilidade está relacionada com a consistência dos resultados obtidos quando o mesmo indivíduo ou objeto é avaliado, medido e/ou quantificado mais do que uma vez. Sem esses dois critérios mencionados acima ficam comprometidos à inferência dos resultados (PASQUALI, 1998).

Ainda de acordo com Pasquali (1998), para avaliar e ou medir uma pesquisa temos que atender a validade e confiabilidade de um instrumento. Para construção de um instrumento de medida existem três procedimentos: teóricos, empíricos (experimentais) e analíticos (estatísticos). No procedimento teórico deve se ter a fundamentação ou explicitação da teoria sobre o construto psicológico que o instrumento pretende medir, para poder ter como um guia na construção dos itens de um instrumento. No procedimento empírico tem-se a coleta de dados por meio do instrumento construído com base na teoria e no procedimento analítico terá a decisão se sua teoria tem ou não alguma consistência, ou seja, a partir da verificação empírica que se pode ou não confirmar a validade de uma teoria "a verda- 
de científica é sempre relativa, nunca será um dogma e, portanto, sempre reformável".

Após a elaboração do instrumento, deve-se verificar a validade do mesmo, onde a validade é a capacidade do instrumento em medir de fato, o que se propõe a medir. Para isso, existem algumas técnicas para realizar essa verificação, como: validação de conteúdo, validação aparente e análise semântica. A validação de conteúdo é a compreensão dos itens com base na teoria, isto é, é a analise item a item feita por juízes qualificados no assunto, na verificação da formulação do item, para que o avaliem quanto ao construto que o mesmo se refere. A validação aparente é a verificação dos itens que não se referem com o objetivo proposto e consequentemente, pode afetar negativamente os resultados finais do instrumento. A análise semântica é a compreensão do item quanto ao seu significado e escrita (PASQUALI, 1998).

A confiabilidade está relacionada com a consistência dos resultados obtidos quando o mesmo indivíduo ou objeto é avaliado, medido e/ou quantificado mais do que uma vez, verificando a constância dos resultados. Existem algumas medidas de confiabilidade que, conforme Martins (2006) são: técnica do teste e re-teste (quando o instrumento é aplicado mais de duas vezes em um mesmo grupo de pessoas); técnicas de formas equivalentes (mesmo instrumento, com duas versões diferentes aplicados a um só grupo); técnicas das metades partidas (o instrumento é dividido em duas metades iguais e aplicado a um só grupo e depois as respostas são comparadas); confiabilidade a partir de avaliadores (quando o instrumento é avaliado por juízes com alta correlação); coeficiente de Alpha de Cronbach (é um valor entre 0 e 1 (ou 0 e 100\%) quanto mais próximo de $100 \%$,melhor é a medição do instrumento), coeficiente KR-20 (também é o grau de confiabilidade e é utilizado quando o teste tem respostas dicotômicas), e outras.

Sem esses dois critérios mencionados, validade e confiabilidade ficam comprometidas à inferência dos resultados. Entretanto, nossa ciência, a psicologia, enfrenta dificuldades semelhantes às de outras áreas do conhecimento; ela nasce e cresce sobre e com a indução. Mas, irá perpassar por toda uma gama de condições sociais e históricas; de modo que, como apontou Gergen (1973) a importância 
da relação entre ciência e sociedade está no fato de que os objetos se alteram com o passar do tempo, diferente das ciências naturais, cujos objetos permanecem. Mas, se a mesma teoria se mantém é porque o problema que a suscitou permanece, e mesmo que de formas diversas, pode ser explicado pelos mesmos determinantes.

Todavia, é possível considerar que o método é o importante protagonista nos avanços do conhecimento das diferentes disciplinas (ou ciências). Sem isso, ainda estaríamos lidando com as crenças e dogmas. A ciência permite conhecer os fenômenos e questioná-los, possibilita o acréscimo de conhecimentos sobre aqueles já adquiridos e possibilita que a humanidade caminhe em uma crescente de conhecimentos sobre as coisas.

O conhecimento científico tido por seu método leva o homem a também conhecer, se adaptar e se apropriar da realidade. Por seu contrário, a falta de conhecimento ou a ignorância anula as possibilidades de progresso. O conhecimento científico nos permite agir com segurança e precisão, nos ajuda a evitar riscos e perigos.

\section{Referências}

ALVES, R. Filosofia da Ciência: introdução ao jogo e a suas regras. $18^{a}$ ed, São Paulo: Loyola, 2013.

APPOLINÁRIO, F. Metodologia da Ciência: Filosofia e Prática da Pesquisa. São Paulo: Cengage Learning, 2011.

CERVO, A.L.; BERVIAN, P.A. Metodologia Científica: para uso dos estudantes universitários. 3.ed. São Paulo: McGraw Hill do Brasil, 1983.

CHIBENI, S. S. Hume e o "dogma do reducionismo". Kriterion, Belo Horizonte , v.52, n.124 p.343-353, 2011. Disponível em: http://www.scielo.br/scielo.php?script=sci_arttext\&pid=S0100-512X2011000200006\&lng=en\&nrm=iso. Acesso em 10 jun 2016

FERREIRA, A.B.H. Mini Dicionário Aurélio da língua portuguesa. 8ª ed. São Paulo: Editora Positivo, 2010.

GERGEN, K. J. Social psychology as history. Journal of Personality and Social Psychology, v.26, n.2, p.309-320, 1973. http://dx.doi.org/10.1037/h0034436

GUTIERRE, J.H.B. A história da ciência e a epistemologia de Popper.In: OLIVEIRA, P. E. (Org.) Ensaios sobre o pensamento de Karl Popper. Curitiba: Círculo de Estudos Bandeirantes, 2012. Disponível em: http://www.pucpr.br/arquivosUpload/1237436911338236651.pdf. Acessado em 20/09/2015. 
KERLINGER, F. Metodologia da pesquisa em ciências sociais. São Paulo: EPU, 1979. KUHN, T.S. A estrutura das revoluções científicas. 5. ed, São Paulo: Perspectiva, 1998. LISTON, G. Verdade e verossimilhança na epistemologia de Popper. In: OLIVEIRA, P. E. (Org.) Ensaios sobre o pensamento de Karl Popper. Curitiba: Círculo de Estudos Bandeirantes, 2012.

Disponível em: http://www.pucpr.br/arquivosUpload/1237436911338236651.pdf. Acessado em 20/09/2015.

LUFT, C P. Dicionário prático de regência verbal. 8. ed. São Paulo: Ática, 2003.

MARCONI, M.A.; LAKATOS, E.M. Metodologia da Pesquisa Científica. São Paulo: Atlas, 2000.

MARTINS, G.A. Sobre Confiabilidade e Validade. Revista Brasileira de Gestão de Negócios, v. 8, n. 20, p. 1-12, jan./abr , 2006.

MEIRELLES, L. Karl Popper, a questão do método científico e seus critérios. Revista do CEFS - Centro de estudos filosóficos de Santos. Ano II, n.11 , 2002. Disponível em:

http://www.paradigmas.com.br/index.php/revista/edicoes-11-a-20/edicao-11/208-karlpopper-a-questao-do-metodo-cientifico-e-seus-criterios. acesso em 10, set 2016.

MENDONÇA, A.L.O.; VIDEIRA,A.A.P. Progresso científico e incomensurabilidade em Thomas Kuhn. Scientiaezudia, São Paulo, v. 5, n. 2, p. 169-83, 2007.

OSTERMANN, F. A. Epistemologia de Kuhn. Cad.Cat.Ens.Fis. do Instituto de Fisica, UFRGS, Porto Alegre, v.13, n3: p.184-196, 1996.

PASQUALI, L. Princípios de elaboração de escalas psicológicas. Rev. Psiquiatr. Clín. São Paulo, v25, n.5, p.206-13, 1998.

POPPER, K.R. Replies to my Critics. In: SCHILPP, P. A. (Org.). The Philosophy of Karl Popper (vol.II), p. 959-1197. La Salle: Open Court, 1974. Disponível em: https:// books.google.com.br/books?id=wxzoBfQYhYAC\&pg=PA341\&lpg=PA341\&dq=The+ Philosophy+of+Karl+Popper+(vol.II)\&source=bl\&ots=CGh9mHo_3-\&sig=7HrcDN eR3qLBd7hK3WyP10UjG7I\&hl=pt-BR\&sa=X\&ved=0CDMQ6AEwA2oVChMI1c72i MyGyAIVRB2QCh23LQWq\# $\mathrm{v}=$ onepage\&q=The $\% 20 \mathrm{Philosophy} \% 20$ of $\% 20 \mathrm{Karl} \% 20$ Popper\%20(vol.II)\&f=false. Acessado em 20/09/2015.

- A lógica da pesquisa científica.São Paulo: Cultrix, 1985.

. Conjectures and Refutations: The Growth of Scientific. Knowledge. London, New York: Routledge, 1989. Disponível em: https://books.google.com.br/ 
books?id=iXp9AwAAQBAJ\&pg=PA594\&dq=Conjectures+and+Refutations:+The+Gro wth+of+Scientific,+Popper\&hl=pt-BR\&sa=X\&ved=0CBwQ6AEwAGoVChMIsbDHs8-GyAIVQxCQCh2IqApV\#v=onepage\&q=Conjectures $\% 20$ and $\% 20$ Refutations $\% 3 \mathrm{~A} \% 20$ The\%20Growth\%20of\%20Scientific\%2C\%20Popper\&f=false. Acessado em 20/09/2015. . The Logic of Scientific Discovery. London and New York: Routledge, 1995. Disponível em: https://books.google.com.br/books?id=cAKCAgAAQBAJ\&printsec $=$ frontcover \&dq=the+logic + Scientific + discovery,+ Popper\&hl=pt=-BR\&sa=X\&ved0CBwQ6AEwAGoVChMI8Kms6tOGyAIVh4KQCh2jkw2q\#v=onepage\&q=the\%20 logic\%20Scientific\%20discovery\%2C\%20Popper\&f=false. Acessado em 20/09/2015.

RUIZ, J. A. Metodologia Científica. São Paulo: Atlas, 1979

VOLPATO, G. Ciência: da filosofia à publicação. São Paulo: Cultura Acadêmica, 2013.

Contato dos autores:

Marília Vizzotto mariliamartinsvizzotto@gmail.com

Valquíria Rossi - valquíria.rossi@metodista.br

Cecília Farhat - cecília.farhat@metodista.br

Recebido em: 27/11/2015

Aceito em10/06/2016 